\title{
Search for alien life reasserts its credibility
}

William Triplett, Washington

The much-maligned Search for Extraterrestrial Intelligence (SETI) programme is slowly rebuilding its credibility in Washington, where some law-makers would like to see NASA restore links with it.

Congress stopped all public funding for SETI in 1994, after some members ridiculed it as squandering taxpayer's money on a quest for "little green men". But the project has made considerable headway since then with private funds, and on 12 July a congressional committee heard testimony on it, as part of an overview hearing on research into whether life exists beyond Earth.

Leaders of the project, which is organized by the SETI Institute in Mountain View, California, say they are not seeking a restoration of government funds. But Christopher Chyba, one of the institute's directors, told the hearing of the space and aeronautics subcommittee of the House Science Committee that the project would like to overturn the current ineligibility of SETI proposals to compete for peer-reviewed grants from NASA's astrobiology programme.

"These grants should be open to SETI researchers to apply for in a peer-reviewed way just as they are for anyone else," says Chyba. He adds that SETI, by searching for other intelligence, is addressing one of astrobiology's central questions.

Since losing its federal funding in 1994, SETI has not only survived but has grown through philanthropic donations, primarily from wealthy technology pioneers such as William Hewlett, David Packard, Gordon Moore, Paul Allen and Barney Oliver.

Michael Meyer, a senior scientist at NASA's astrobiology programme, says that

\section{Action urged to combat killer algae}

Rex Dalton, San Diego

More than a year after invasive algae took root along the southern California coast, authorities have yet to arrange a thorough scientific study of either the algae or the programme to eradicate them.

At a workshop held on 10-11 July in San Diego, a sub-panel of the US Aquatic Nuisance Species Task Force agreed that such studies were urgently needed to combat Caulerpa taxifolia, which has infested two lagoons in southern California.

"Research and peer review must go hand-in-hand with eradication and control efforts," says Steven Miller, director of the National Undersea Research Center at the University of North Carolina and chair of the panel, which is preparing a national action plan to fight future infestations.

C. taxifolia is indigenous to the Caribbean, but a strain of the algae has already destroyed large areas of natural habitat in the Mediterranean after it was inadvertently released near Monaco in 1988 . The fastgrowing algae are toxic to some marine life and have no natural enemies in the areas they have invaded.

In California, the algal growths - some estimated to be as large as $\mathbf{3 0}$ tonnes - were identified in June last year (see Nature 406, 447; 2000).

The source of the algae is unknown, but the authorities suspect that they were dumped by aquarium enthusiasts who use them in their tanks. A bill is moving through the California legislature to outlaw the sale and possession of $C$. taxifolia and eight other similar algae, but it has faced opposition from the home aquarium business.

Susan Williams, director of the Bodega Marine Laboratory at the University of California, Davis, has spent the past year pressing for research and outside peerreview of the eradication effort. She says she has been unsuccessful because of resistance by some state and federal officials who want to concentrate resources on eradication.

The \$1-million eradication effort involves placing tarpaulins over patches of algae and injecting chlorine underneath to kill them.

There is evidence that the chlorine has killed algae under the tarpaulins, the workshop was told. But patches of the algae have also cropped up outside the tarpaulins.

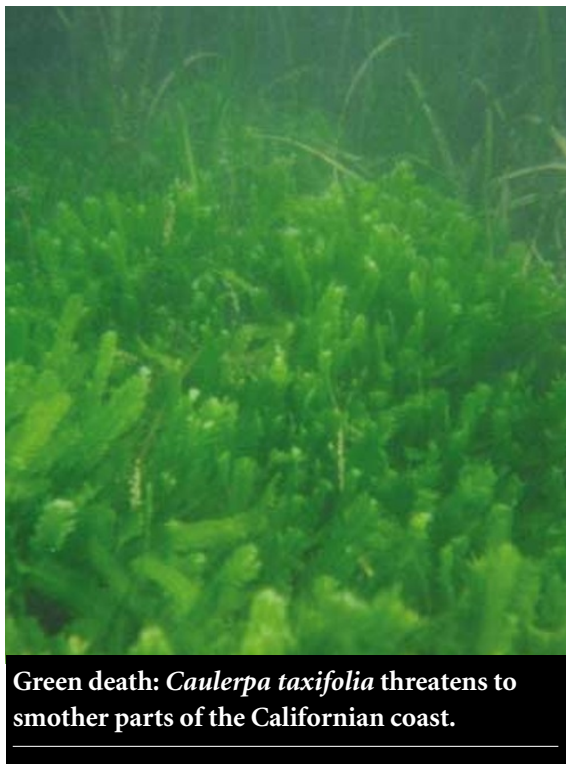

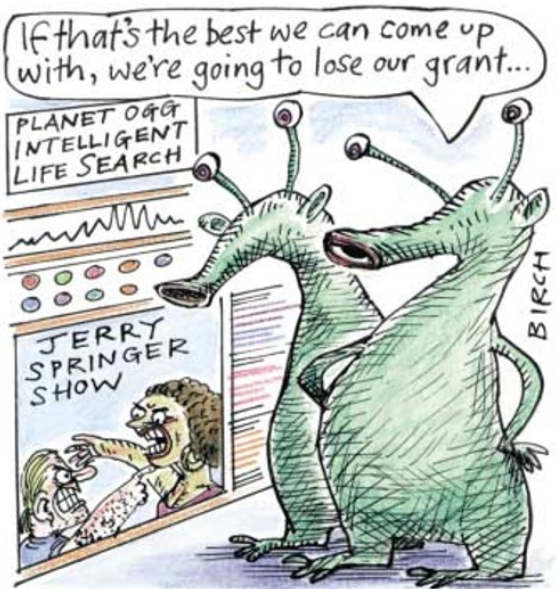

as a result of the congressional language used in removing SETI from the federal budget, the agency is effectively prohibited from funding SETI-specific activities even through grants, which are awarded only to proposals involving "good science".

SETI critics have argued in the past that SETI does not constitute good science. But Lamar Smith (Republican, Texas), whose enthusiasm for the project led to the hearing taking place, noted that SETI's track record has improved markedly in recent years.

Indeed, Chyba points out that successive decadal reviews of astronomy by the National Academy of Sciences have endorsed SETI. The most recent one singled out the project for pioneering new technology that will have other useful applications.

But whether NASA is ready to offer astrobiology grants to SETI is another matter. "The SETI Institute has been very successful and they do some good stuff," says Meyer. "But there's the issue of once burnt, twice shy. We're growing an astrobiology programme that seems to be fantastically popular with not only the public but with the White House Office of Management and Budget and with Congress and even within NASA. But there could be concern that if we include SETI in this, while intellectually it fits within the programme, all of a sudden the enthusiasm you had gets turned back into why are we looking for little green men?"

But Smith told the hearing: "The discovery of life in the Universe would be one of the most astounding discoveries in human history. Funding should match public interest and I don't believe it does." He was backed up by Zoe Lofgren (Democrat, California). According to one congressional staff member, Congress is moving slowly towards an acceptance, if not an embrace, of SETI. "There's really no groundswell for restoring a federal funding line for SETI right now," says the staffer. "Then again, there's no real opposition to it, either."

http://www.seti-inst.edu 